\title{
Wnt Signaling in Mammalian Development: Lessons from Mouse Genetics
}

\author{
Jianbo Wang ${ }^{1}$, Tanvi Sinha ${ }^{1}$, and Anthony Wynshaw-Boris ${ }^{2}$ \\ ${ }^{1}$ Department of Cell Biology, School of Medicine, University of Alabama at Birmingham, Birmingham, \\ Alabama 35294 \\ ${ }^{2}$ Department of Pediatrics and Institute for Human Genetics, School of Medicine, University of California \\ San Francisco, San Francisco, California 94143-0794 \\ Correspondence: j18wang@uab.edu and wynshawborist@peds.ucsf.edu
}

Wnts are evolutionarily conserved signaling ligands critical for animal development. Genetic engineering in the mouse has enabled investigators to acquire a detailed activation profile of the $\beta$-catenin-dependent canonical Wnt pathway during mouse development, and to manipulate Wnt pathway activities with great spatial and temporal precision. Together, these studies have not only revealed important functions of Wnt signaling at multiple stages of early mouse development, but also elucidated how the Wnt pathway interacts with other pathways to form signaling networks that confer the unique features of mammalian embryogenesis. Additionally, the planar cell polarity pathway has emerged as an essential $\beta$-catenin independent noncanonical Wnt pathway that coordinates cell polarity and regulates tissue morphogenesis in various mammalian developmental processes. Importantly, studies of Wnt signaling in mouse development have also revealed important pathogenic mechanisms of several congenital disorders in humans.

\begin{abstract}
mong the model organisms used for studyAing Wnt signaling, the mouse shares the greatest genetic, structural, and physiological similarities with humans. Genetic studies in mice, therefore, provide the most direct insight in the role of Wnt signaling in human biology and diseases. Both mice and humans have 19 Wnt ligands and 10 Frizzled (Fz) receptors. Based on studies in Drosophila, Xenopus, and zebrafish, Wnt signaling can be broadly divided into the canonical Wnt pathway that involves $\beta$-catenin-mediated transcriptional activation, and the noncanonical Wnt pathway that is $\beta$ catenin independent but shares some components with the canonical Wnt pathway. In this
\end{abstract}

review, we will discuss how both canonical and noncanonical Wnt signaling contributes to the unique developmental processes in mammals.

\section{THE ROLE OF CANONICAL WNT \\ SIGNALING IN EARLY MOUSE DEVELOPMENT}

In mice, as in flies and Xenopus, canonical Wnt signaling is initiated by binding of Wnt ligands to Fz receptors and coreceptors Lrp5/6, which recruits Dishevelled (Dvl) to inhibit the destruction complex from phosphorylating and earmarking $\beta$-catenin for degradation. Consequently, $\beta$-catenin is stabilized and translocated

Editors: Roel Nusse, Xi He, and Renee van Amerongen

Additional Perspectives on Wnt Signaling available at www.cshperspectives.org

Copyright (C) 2012 Cold Spring Harbor Laboratory Press; all rights reserved; doi: 10.1101/cshperspect.a007963

Cite this article as Cold Spring Harb Perspect Biol 2012;4:a007963 
J. Wang et al.

to the nucleus, where it binds to transcription factors Tcf/Lef (T-cell transcription factor/ lymphocyte enhancer factor) to activate target gene transcription. Based on this paradigm, several very useful mouse lines were created. First, because there is only one $\beta$-catenin in the mouse, canonical Wnt signaling can be completely abolished by deleting $\beta$-catenin. Consequently, a set of $\beta$-catenin null and LoxP flanked ( floxed) conditional null alleles were established (reviewed by Grigoryan et al. 2008). In many cases, these $\beta$-catenin loss-of-function (LOF) mutants have allowed investigators to bypass the genetic redundancy issues associated with virtually all other components of the pathway and determine how complete loss of Wnt signaling affects development. Second, because exon 3 of $\beta$-catenin encodes all the residues responsible for its phosphorylation and degradation, deleting exon3 leads to stabilized $\beta$-catenin that constitutively activates canonical Wnt signaling. An exon3-floxed, conditional $\beta$-catenin gain-offunction (GOF) allele was established to study how proper control of Wnt signaling activity contributes to development (Harada et al. 1999; Grigoryan et al. 2008). Third, because $\beta$-catenin activates gene transcription through Tcf/Lef, a number of Wnt reporter lines were established by placing LacZ or EGFP cassette behind promoters that contain multiple TCF/ LEF binding sites, allowing visualization of canonical Wnt signaling activity by $\beta$-galactosidase ( $\beta$-gal) staining or GFP fluorescence (Jho et al. 2002; Lustig et al. 2002; Maretto et al. 2003; Mohamed et al. 2004; Currier et al. 2010). The use of these reporters in conjunction with $\beta$ catenin mutants and an array of other mutants have helped us understand the role of the Wnt pathway in early mouse development.

\section{Implantation}

In mice, the fertilized egg undergoes several rounds of cleavages and by embryonic day (E) 3.5 , forms the blastocyst that contains an inner cell mass (ICM) surrounded by a layer of trophoblast epithelium (trophectoderm) (Fig. 1A). The trophoblast attaches and invades the maternal uterine epithelium during implanta- tion at E4.5, while the ICM rapidly proliferates to form the epiblast where the entire embryo originates, and the primitive endoderm that encloses the epiblast (Fig. 1B).

In preimplantation blastocysts, a number of Wnts are expressed in the ICM or the trophectoderm (Kemp et al. 2005). Early analyses of Wnt reporters or immunostaining for stabilized, nonphosphorylated $\beta$-catenin failed to detect active canonical Wnt signaling in the embryos at this stage (Mohamed et al. 2004). However, a recent study, using a different Wnt reporter, revealed a transient activation of Wnt signaling in the ICM, which is extinguished on implantation (ten Berge et al. 2011). Consistent with this observation, this recent study also found that Wnt signaling activation is required to maintain the undifferentiated state of ICMderived embryonic stem cells in vitro (ten Berge et al. 2011). Whether Wnt signaling is similarly required within the embryo for preimplantation development, however, remains unclear because both $\beta$-catenin and Lrp5/6 null mutants display no overt defects prior to implantation (Huelsken et al. 2000; Kelly et al. 2004). Furthermore, it is interesting to note that even when the stabilized $\beta$-catenin GOF mutant is ectopically expressed from the oocyte stage, no aberrant accumulation of $\beta$-catenin or Wnt signaling activation was detected before implantation (Kemler et al. 2004), suggesting that mechanisms in addition to the destruction complex must be restricting $\beta$-catenin accumulation/ nuclear translocation during preimplantation.

The Wnt ligands secreted by the blastocyst may also trigger signaling activation in the maternal uterine epithelium during implantation. Analysis of Wnt reporters showed Wnt signaling activation in the uterine epithelium adjacent to the implanting blastocyst. Luminal injection of Wnt7a medium or coated beads could induce Wnt reporter activation, whereas injection of a Wnt antagonist, Sfrp2 (secreted Frizzled-related protein), significantly reduced implantation efficiency (Mohamed et al. 2005). Therefore, Wnt signaling activation in the uterine epithelium, likely induced by the blastocyst, may be functionally important for the implantation process. 
Wnt Signaling in Mammalian Development
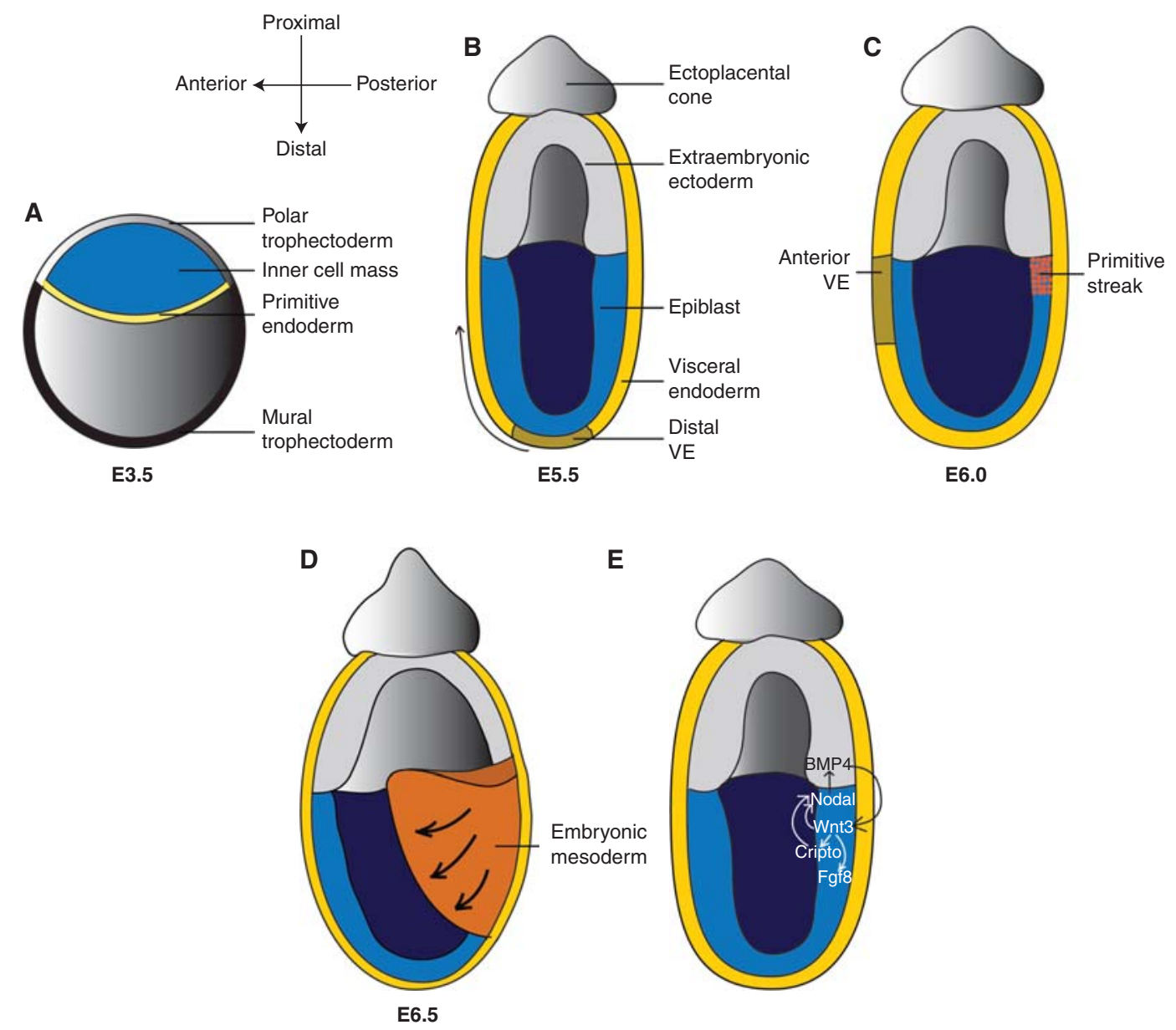

Figure 1. Early mouse development and the role of Wnt3 in mammalian gastrulation. (A) Preimplantation blastocyst stage mouse embryo. (B) After implantation, the inner cell mass (ICM) expands into a radially symmetric cup of epithelium known as the epiblast that gives rise to the entire embryo proper. The polar trophectoderm, initially overlying the ICM, gives rise to the ectoplacental cone and the extraembryonic ectoderm (ExE) that do not contribute to the embryo proper, but form the placenta and trophoblast giant cells to support embryonic development. The ExE and epiblast is also covered by a layer of visceral endoderm (VE) derived from the primitive endoerm in the blastocyst. $(C)$ Between E5.5 and 6.0, the distal VE undergo proximally oriented unidirectional movement, leading to the formation of the anterior VE (AVE) that marks the future anterior side of the embryo. The AVE inhibits Nodal signaling anteriorly to restrict Nodal-induced primitive streak formation in the posterior epiblast adjacent to the ExE. (D) During gastrulation, epiblast cells ingress through the primitive streak to give rise to the mesoderm and definitive endoderm. (E) Wnt3-induced canonical Wnt signaling is an integral part of a global signaling network that regulates gastrulation. Epiblastderived Nodal activates the expression of Bmp4 in the neighboring ExE. Bmp4 signals back to activate Wnt3 expression in the epiblast. In turn, Wnt3 potentiates Nodal signaling by promoting the expression of Nodal and its coreceptor Cripto (important for Nodal auto-induction), thereby establishing the Nodal-Bmp4-Wnt3 positive feedback loop to sustain gastrulation. In addition, Wnt3 is also required for Fgf8 expression, which promotes ingressing epiblast cells to migrate out of the primitive streak during gastrulation. 
J. Wang et al.

Postimplantation Development: AnteriorPosterior (A-P) Axis Formation and Gastrulation

By E5.5, shortly after implantation, the ICMderived epiblast expands into a radially symmetric cup of epithelium (Fig. 1B). Proximally, the epiblast is adjacent to the extraembryonic ectoderm (ExE) derived from the polar trophectoderm, a subset of the trophectoderm apposing the ICM in the blastocyst (Fig. 1A). Both the epiblast and the ExE are covered by the visceral endoderm (VE), a single layer epithelium derived from the primitive endoderm.

E5.5 embryos display polarity only along the proximal-distal (P-D) axis from the ExE to the epiblast (Fig. 1B). Coordinated cell movement then rotates the P-D axis to establish the A-P axis: between E5.5 and 6.0, the VE cells at the distal tip of the embryo undergo proximally oriented unidirectional movement, leading to the formation of the anterior VE (AVE, Fig. 1B and $\mathrm{C}$ ). The AVE marks the future anterior side of the embryo and patterns the underlying epiblast to form the head. The AVE also represses Nodal signaling to restrict the formation of the primitive streak to the proximal-posterior epiblast adjacent to the ExE between E6.0 to 6.5 (Fig. 1C) (Perea-Gomez et al. 2002; Stuckey et al. 2011). During gastrulation from E6.57.5 , posterior epiblast cells undergo epithelial to mesenchymal transition and ingress through the primitive streak to give rise to the mesoderm and definitive endoderm (Fig. 1D) while the anterior epiblast forms the neural and surface ectoderm. Therefore, gastrulation establishes the three germ layers and a basic body plan.

Analyses of several Wnt reporters showed that their expression can be first detected consistently at E6.0 in the proximal-posterior epiblast in which the primitive streak will form (Fig. 1C); and as gastrulation proceeds, their expression extends distally in the epiblast, marking the forming primitive streak (Maretto et al. 2003; Mohamed et al. 2004; Currier et al. 2010). These studies suggest that canonical Wnt signaling is activated in the primitive streak from the onset of gastrulation. Indeed, several presumptive canonical Wnt genes, including $W n t 2 b$, Wnt3, and
$W n t 8 a$, are expressed in a pattern very similar to the Wnt reporter activities prior to and during gastrulation (Liu et al. 1999; Yamaguchi 2008).

Genetic studies in the mouse showed that canonical Wnt signaling is also functionally required for gastrulation. In $W n t 3^{-/-}$mutants, the primitive streak does not form and gastrulation does not occur (Liu et al. 1999; Barrow et al. 2007). Almost identical defects are observed when the function of both Lrp5 and -6 are disrupted in $\mathrm{Lrp5}^{-/-} ; \mathrm{Lrp6}^{-/-}$mutants or mesd (mesoderm development) mutants, which lacks a chaperone specifically required for trafficking Lrp5/6 to the plasma membrane (Hsieh et al. 2003; Kelly et al. 2004). Intriguingly, loss of $W n t 2 b$ or Wnt8a causes no embryonic defects (Yamaguchi 2008). Therefore, Wnt3 per se is both necessary and sufficient for activating Wnt signaling to initiate primitive streak formation and gastrulation.

More recent studies revealed that the canonical Wnt pathway is an integral part of a global signaling network that regulates gastrulation (Fig. 1E). Wnt3 expression relies on Nodal, a Tgf $\beta$ ligand whose expression in the epiblast regulates P-D and A-P axes formation as well as gastrulation (Robertson et al. 2003). Nodal, however, regulates Wnt3 expression indirectly through activating the expression of $B m p 4$, another Tgf $\beta$ family ligand, in the neighboring ExE (Ben-Haim et al.2006). Bmp4 signals back to the adjacent epiblast to activate Wnt3 expression (Ben-Haim et al. 2006; Miura et al. 2010). In turn, Wnt3 potentiates Nodal signaling by promoting the expression of Nodal and its coreceptor Cripto (Morkel et al. 2003; Ben-Haim et al. 2006), thereby establishing a Nodal-Bmp4Wnt3 positive feedback loop to sustain gastrulation. In addition, Wnt 3 is also required for Fgf8 expression in the primitive streak, which activates Fgf signaling to promote ingressing epiblast cells to migrate out of the streak during gastrulation (Sun et al. 1999; Morkel et al. 2003).

Consistent with $\beta$-catenin playing a central role in canonical Wnt signaling, $\beta$-catenin null mutants recapitulate the gastrulation defect in Lrp5/6 and Wnt3 mutants (Haegel et al. 1995; Huelsken et al. 2000). Unlike Lrp5/6 and Wnt3 
mutants, though, $\beta$-catenin ${ }^{-/-}$mutants display an additional defect in A-P axis formation, because the distal VE fails to move proximally to form the AVE (Huelsken et al. 2000). Earlier studies attributed this defect to a more severe disruption of Cripto expression in $\beta$-catenin ${ }^{-/-}$ mutants, because Cripto is a presumptive transcriptional target of $\beta$-catenin and a Nodal coreceptor essential for AVE migration (Ding et al. 1998; Morkel et al. 2003). However, Cripto expression is earlier and much broader than Wnt reporter expression that marks $\beta$-catenin induced transcriptional activity (Mohamed et al. 2004; ten Berge et al. 2008). Furthermore, in $\beta$ catenin GOF mutants, Cripto is highly expressed yet the AVE fails to form (Morkel et al. 2003). Therefore, whether the AVE defect in $\beta$-cate$\mathrm{nin}^{-/-}$mutants is solely caused by the disruption of Cripto expression needs further investigation. Another study proposed that AVE migration might be propelled by a gradient of canonical Wnt signaling activity in the VE, established by Wnt3 and its extracellular inhibitors, such as Dkk1 (Dickkopf1), expressed in the prospective posterior and anterior side, respectively (Kimura-Yoshida et al. 2005). However, this hypothesis is not consistent with the chimera analyses of $\beta$-catenin ${ }^{-/-}$mutants, which concluded that $\beta$-catenin is required only in the epiblast, but not in the VE, for proper A-P axis formation (Huelsken et al. 2000). A third possibility is that the AVE defect in $\beta$-catenin ${ }^{-/-}$mutants may originate from cell proliferation defects. A recent study revealed that during AVE movement in wild-type embryos, the cell proliferation rate in the epiblast is 11-fold higher than that in the $\mathrm{VE}$, and that this growth disparity is required to drive AVE migration (Stuckey et al. 2011). Therefore, the reduced cell proliferation manifested by $\beta$-catenin ${ }^{-/-}$mutant at pregastrulation stage (Huelsken et al. 2000) may also contribute to the failure of AVE migration.

Considering the indispensable role of Lrp5/ 6 and its homolog Arrow in Wnt signal transduction, it is intriguing that Lrp5/6 and mesd mutants do not display the AVE defect manifested by $\beta$-catenin mutants (Hsieh et al. 2003; Kelly et al. 2004). It was proposed that this phenotypic difference may arise from a ligand-in- dependent transcriptional activity of $\beta$-catenin in the mouse (Morkel et al. 2003). However, it is important to note that in addition to activating transcription in the Wnt pathway, $\beta$-catenin also functions as a structural protein to maintain adherens junctions (Nelson and Nusse 2004). Although $\beta$ - catenin $^{-/-}$mutants do not display overt disruption of cell adhesion owing to the compensatory substitution by plakoglobin (Huelsken et al. 2000; Lickert et al. 2002), loss of $\beta$-catenin may interfere with rapid cell proliferation that may not be sustained by plakoglobin alone, or morphogenetic movements in which plakoglobin may not be sufficient to confer the required dynamic remodeling of adherens junctions.

\section{Wnt Signaling Suppression in Anterior Patterning}

Although Wnt signaling activation is required for primitive streak formation and posterior patterning, it must be suppressed anteriorly for proper patterning of the anterior epiblast. Dkk1, which antagonizes Wnt signaling by binding to Lrp $5 / 6$, is initially expressed in a crescent-shaped domain around the AVE, and later in the primitive streak-derived anterior mesendoderm (AME) (Mukhopadhyay et al. 2001; Kimura-Yoshida et al. 2005). In $D k k 1^{-/-}$null mutants, Wnt reporter expression expands anteriorly from E7.0 and head truncation occurs by E9.5 (Mukhopadhyay et al. 2001; Lewis et al. 2008). Chimera analysis indicated that AVEderived Dkk1 is dispensable, whereas AME-derived Dkk1 is sufficient for anterior head patterning (Mukhopadhyay et al. 2001). Interestingly, the head truncation defect in $D k k 1^{-/-}$mutants can be partially suppressed by halving the dosage of Wnt3 (Lewis et al. 2008), indicating that a major function of Dkk1 is to modulate Wnt3 induced Wnt signaling. Furthermore, proper anterior patterning also requires inhibition of $\beta$-catenin mediated transactivation by ICAT (Inhibitor of $\beta$-catenin and $\mathrm{T}$ cell factor), an 81 amino acid protein that disrupts the interaction between $\beta$-catenin and TCF. ICAT ${ }^{-/-}$mice display head truncation defect similar to that in $D k k 1^{-/-}$mutants (Satoh et al. 2004). 
J. Wang et al.

Tail Bud Formation, Somitogenesis, and Left-Right Determination

After gastrulation, Wnt3 expression is downregulated and eventually terminated by E8.5 (Liu et al. 1999). However, the primitive streak and its derivative, the tail bud, continue to produce mesoderm for another 5 days to form the paraxial presomitic mesoderm (PSM) and lateral plate mesoderm (LPM) that give rise to the trunk and tail. Analyses of Wnt reporters indicate that canonical Wnt signaling remains active in the primitive streak/tail bud, and this is due in part to Wnt3a, another canonical Wnt that starts to be expressed in the primitive streak from E7.5 (Nakaya et al. 2005). Wnt3a $a^{-/-}$mutants fail to form posterior mesoderm and the tail bud but instead develop ectopic neural tissue, indicating that Wnt3a is required for the maintenance and the function of the primitive streak (Takada et al. 1994; Yoshikawa et al. 1997). One of the most critical targets of Wnt3a is $T$ (Brachyury), a transcription factor required for mesoderm formation (Fig. 2) (Yamaguchi et al. 1999b). $T$ contains multiple Lef1 binding sites that are required for maintaining, but not initiating, $T$ expression in the primitive streak and nascent mesoderm (Galceran et al. 2001). Finally, similar to Wnt3a and T mutants, Lef1/ Tcf1 double null mutants lack posterior mesoderm and develop ectopic neural tubes, whereas expression of a constitutively active Lef1- $\beta$-catenin fusion can suppress the defects in Wnt3a mutants, proving definitively that Wnt3a signals through the canonical Wnt pathway to regulate mesoderm formation (Galceran et al. 1999, 2001; Yamaguchi et al. 1999b).

Wnt3a secreted from the primitive streak also activates Wnt signaling in the flanking PSM, which undergoes periodic boundary formation that cleaves off a segment of the anterior PSM to form a somite every 2 hours along the A-P axis (Yamaguchi 2008). Rhythmic formation of somites requires a "segmentation clock," manifested as oscillating activation of the Notch signaling pathway in the PSM (Pourquie 2011). Wnt3a-induced Wnt signaling regulates the segmentation clock, at least in part, by activating Notch ligand Dll1 (Delta-like1)

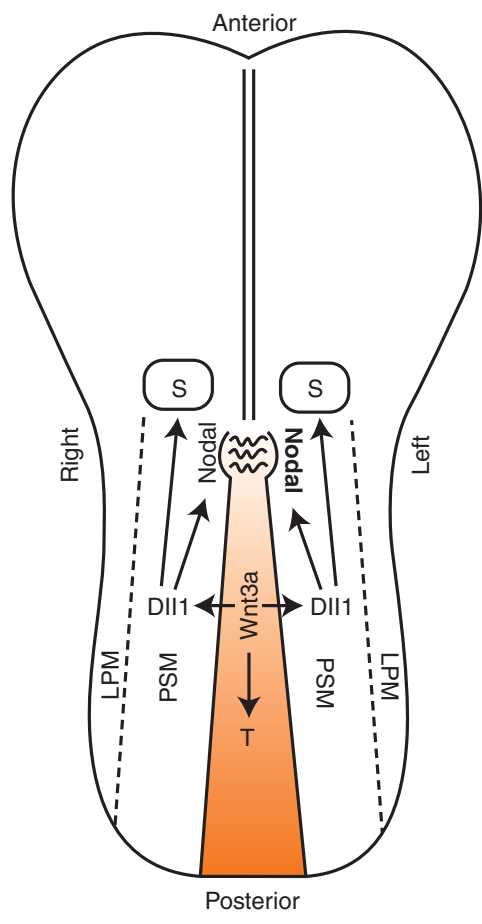

Figure 2. The role Wnt3a in early postgastrulation mouse development. A schematic diagram of the ventral view of an early postgastrulation (E8.0) mouse embryo showing that expression of Wnt3a in the primitive streak activates canonical Wnt signaling to maintain T (Brachyury) expression, thereby sustaining mesoderm production. Primitive streak-derived Wnt3a also signals to the adjacent paraxial presomatic mesoderm (PSM) to active Notch ligand Dll1 expression to regulate somitogenesis. Wnt3a-activated Dll1 expression in the PSM also regulates Nodal expression at the periphery of the node. Left-ward flow generated by rotating node cilia then enhances Nodal signaling and eventually, Nodal expression, on the left side of the node, leading to the L-R axis determination. Dll1, Delta 1; PSM, presomitic mesoderm; LSM, lateral plate mesoderm; S, somite; T, Brachyury.

transcription in the PSM (Fig. 2) (Galceran et al. 2004; Hofmann et al. 2004; Nakaya et al. 2005). Secondly, a gradient of Wnt signaling activity, likely established by the graded expression of Wnt3a along the A-P axis, is thought to constitute part of the "determination wavefront" that positions the segmentation boundary during somitogenesis (Pourquie 2011). By manipulating Wnt activity gradient using $\beta$-catenin LOF and GOF mutants, studies show that high level 
Wnt Signaling in Mammalian Development

Wnt activity maintains posterior PSM in an undifferentiated state permissive of Notch signaling oscillation, while a gradual reduction of Wnt activity in the anterior PSM sets the boundary to arrest Notch signaling oscillation and to activate genes required for segment formation (Aulehla et al. 2008; Dunty et al. 2008).

Wnt3a is also required for left-right (L-R) axis determination because $W n t 3 a$ null mutants display laterality defects in multiple visceral organs (Nakaya et al. 2005). In mice, L-R determination relies on Nodal expression at the periphery of the node, a specialized structure located immediately rostral to the primitive streak (Fig. 2) (Brennan et al. 2002). Nodal is initially expressed symmetrically along both the right and left side of the node, but a leftward flow generated by node cilia rotation (see below) causes enhanced Nodal signaling on the left node, eventually breaking the L-R symmetry by up-regulating Nodal expression in the left node and left LPM. In Wnt3a mutants, Nodal expression in the node is diminished, leading to delayed and symmetric Nodal expression in the LPM and defective expression of several other genes essential for L-R determination, including Lefty1/2 and Pitx2 (Nakaya et al. 2005). Because Nodal expression in the node depends on Notch signaling, Wnt3a is thought to regulate L$\mathrm{R}$ determination indirectly by activating Dll1 expression in the adjacent PSM (Fig. 2) (Nakaya et al. 2005). In light of the finding that Wnt3 may regulate Nodal expression directly during gastrulation (Ben-Haim et al. 2006), it is possible that primitive streak-derived Wnt3a may also directly activate Nodal expression in the node.

\section{NONCANONICAL WNT/PLANAR CELL POLARITY PATHWAY SIGNALING IN MOUSE DEVELOPMENT}

Studies in zebrafish, Xenopus, and tissue culture have found that some Wnt ligands, such as Wnt5a and Wnt11, or overexpression of some Fz receptors, do not lead to $\beta$-catenin stabilization, but instead lead to divergent downstream events collectively termed the noncanonical Wnt signaling, which include JNK, $\mathrm{Ca}^{2+}$, and small GTPase Rho/Rac/Cdc42 signaling activa- tion (Veeman et al. 2003; Wallingford and Habas 2005). Because these downstream signaling events are diverse and may also serve as signaling outputs of many other pathways, currently we do not have an assay that can specifically determine noncanonical Wnt signaling activation. Therefore, our current understanding of noncanonical Wnt signaling in mouse development has been mostly limited to one branch known as the planar cell polarity (PCP) pathway, in which pioneering studies in Drosophila have identified most of the genetic components and provided critical mechanistic insights (Seifert and Mlodzik 2007; Zallen 2007; Strutt and Strutt 2009; Bayly and Axelrod 2011).

In flies, the PCP pathway coordinates cellular polarity on the plane of the epithelium, perpendicular to the apical-basal (A-B) polarity of the cell. Examples of PCP include uniformly oriented trichomes on the wing epithelium and bristles on the abdomen (Lawrence et al. 2004; Seifert and Mlodzik 2007). The PCP pathway shares $\mathrm{Fz}$ and Dvl with the canonical Wnt pathway, but also requires a distinct set of membrane or cytoplasmic proteins, including Flamingo, Diego, Prickle, and Van Gogh (Vang). Studies of these "core" PCP gene orthologs in Xenopus and zebrafish revealed an essential role of PCP signaling in convergent extension (CE), a morphogenetic process during which tissues elongate anterior-posteriorly and concomitantly narrow medial-laterally. During CE, PCP signaling has been shown to regulate polarized cell intercalation in mesodermal cells in Xenopus, and also to promote directional cell migration and oriented cell division in zebrafish (Heisenberg et al. 2000; Wallingford et al. 2000; Gong et al. 2004; Roszko et al. 2009). In light of these findings, mouse genetic studies have uncovered many important roles of PCP signaling in coordinating cell polarity and tissue morphogenesis in mammals.

\section{Cell Polarity Establishment}

\section{Epiblast Cell Polarity}

The canonical Wnt pathway is not the only Wnt related pathway important for gastrulation. Recently, Tao et al. found that the deletion of the 
J. Wang et al.

mouse Prickle homolog, $m p k 1$, resulted in early embryonic lethality, between E5.5 and E6.5, associated with failure of distal VE migration and primitive streak formation (Tao et al. 2009). Mutant epiblast tissue was disorganized, and epiblast cells displayed abnormal cell shapes, mislocalized extracellular matrix (ECM) proteins, and disrupted orientation of mitotic spindles with loss of A-B polarity of epiblast cells. They showed that $m p k 1$ genetically interacts with another core PCP gene Vangl2 (an ortholog of Vang) in epiblast formation, suggesting that PCP components are commonly required for the establishment and/or the maintenance of epiblast A-B polarity. Thus, the PCP pathway may play a very early role in postimplantation establishment of A-P polarity and gastrulation.

\section{Nodal Cilia}

It was recently found that the three $D v l$ genes participate in the planar polarization of node cells to determine the rotational axis of nodal cilia (Hashimoto et al. 2010). Rotational movement of the node cilia generates a leftward fluid flow (see Fig. 2) in the mouse embryo because the cilia are posteriorly tilted (Nonaka et al. 2005; Okada et al. 2005), but it was not known how A-P information is translated into the posterior tilt of the node cilia. We found that the basal body of node cilia is initially positioned centrally but then gradually shifts toward the posterior side of the node cells, a shift that was impaired along with malpositioning of the basal body and unidirectional nodal flow in compound mutant mice lacking $D v l$ genes. The basal body was normally positioned in the node cells of $W n t 3 a^{-/-}$embryos (coding for a canonical Wnt involved in gastrulation), but inhibition of Rac1, a downstream effector of the noncanonical Wnt signaling pathway, impaired the polarized localization of the basal body in wild-type embryos. Dvl2-EGFP and Dvl3-EYFP proteins were localized to the apical side of the node cells, and their location was polarized to the posterior side of the cells before the posterior positioning of the basal body. Thus, posterior positioning of the basal body to provide posterior tilt to node cilia is determined by planar polarization mediated by noncanonical Wnt/PCP signaling. This interpretation was definitively proven when it was found that Vangl1/2 double mutants displayed identical nodal cilia placement defects, resulting in disruption of leftward nodal flow and L-R asymmetry defects (Song et al. 2010). Vangl1 and -2 are thought to be exclusively part of the PCP pathway, unlike Dvls, which participate in canonical Wnt and noncanonical PCP pathways.

\section{Stereociliary Bundle Orientation}

The mammalian auditory sensory organ, the organ of Corti, consists of four rows of sensory hair cells along the lateral side of the cochlea duct. On the apical surface of each hair cell, there are a set of actin-filled microvilli called stereocilia that are organized into a $\mathrm{V}$-shaped staircase. The vertex of each V-shaped stereociliary bundle is always pointed toward the lateral side of the cochlea, thereby displaying a distinct polarity reminiscent of fly PCP (Rida and Chen 2009). Indeed, in Looptail mutant mice (Vangl2 ${ }^{L p / L p}$ ) that harbor a spontaneous loss-of-function mutation in Vangl2, the stereociliary orientation becomes randomized, suggesting that a conserved mammalian PCP pathway is required to coordinate stereociliary orientation among hair cells (Montcouquiol et al. 2003). This hypothesis was validated by the findings of similar stereociliary orientation defects in mouse mutants of other PCP orthologs, including Celsr1 (an ortholog of flamingo [Curtin et al. 2003]), Fz3 and -6 (Wang et al. 2006b) and Dvl1, -2, and -3 (Wang et al. 2005; Etheridge et al. 2008). Furthermore, mouse PCP proteins display asymmetric plasma membrane distribution in the organ of Corti, and mutation of one PCP gene perturbs the membrane localization of other PCP proteins (Wang et al. 2005, 2006b; Montcouquiol et al. 2006; Jones et al. 2008). The asymmetric membrane localization of PCP proteins is a unique feature first described in flies and is thought to provide a mechanism for PCP proteins to propagate polarity information across the entire field of 
Wnt Signaling in Mammalian Development

epithelium (Amonlirdviman et al. 2005; Wu and Mlodzik 2008). Lastly, the asymmetric distribution of PCP proteins is observed prior to overt morphological polarization of stereociliary bundles (Wang et al. 2006a; Jones et al. 2008), consistent with PCP signaling playing a role in establishing stereocilia orientation in mice.

Although the above findings showed unequivocally that a mechanism highly conserved with the fly PCP pathway is involved in coordinating stereocilia orientation in mice, studies have also identified several genes that are indispensable for mouse PCP signaling, but are not known for fly PCP signaling. These include Scribble1 (Scrb1, homologous to fly scribble) known to be involved in apical-basal polarity determination (Bilder and Perrimon 2000; Montcouquiol et al. 2003), and two transmembrane tyrosine kinases Ptk7 and Ror2 (Lu et al. 2004; Yamamoto et al. 2008; Gao et al. 2011). In vertebrates, Ptk7 may function by recruiting Dvl to the plasma membrane (Wehner et al. 2011), whereas Ror2 may function together with $\mathrm{Fz}$ as a coreceptor for Wnt5a (Oishi et al. 2003; Yamamoto et al. 2008; Gao et al. 2011). Mutations in Wnt5a cause minor stereocilia mis-orientation and $W n t 5 a$ genetically interacts with Vangl2 (Qian et al. 2007). Therefore, noncanonical Wnt ligands seem to be involved in PCP signaling during stereocilia orientation in mice. In contrast, studies in flies concluded that Wnt ligand is not required for PCP signaling (Povelones et al. 2005).

Another interesting finding in mice is that proper stereocilia orientation requires intact kinocilium, a single microtubule-filled primary cilium (similar to nodal cilium) located at the vertex of each $\mathrm{V}$-shaped stereociliary bundle. Mutations that abolish kinocilium formation cause randomized stereocilia orientation despite proper asymmetric membrane localization of PCP proteins (Jones et al. 2008). These observations have led to the proposal that PCP signaling functions by providing cell-cell communication to establish coordinated polarity among adjacent cells, but not by specifying the intrinsic polarity within each cell in an instructive fashion (Rida and Chen 2009).

\section{Hair Follicle Orientation}

Mouse PCP signaling coordinates not only the orientation of stereocilia and nodal cilia that arise on single cells, but also the alignment of body hairs originating from hair follicles consisting of hundreds of cells. A detailed study showed that before basal epidermal cells invaginate to form hair follicles, PCP proteins are already enriched along their anterior and posterior plasma membrane. During invagination, only cells on the anterior side constrict basally, causing each hair follicle to form an anterior tilt that aligns with the global A-P axis of the body. In Vangl2 and Celsr1 embryos, anterior cells fail to undergo basal constriction, resulting in hair follicles that initially lack any tilt and later orient randomly (Devenport and Fuchs 2008). In $\mathrm{Fz}^{-/-}$mice that survive postnatally, there are abnormal hair whorls, tufts, and waves throughout the body (Guo et al. 2004). Collectively, these results suggest that PCP signaling can orchestrate global hair follicle morphogenesis to control the directionality of body hairs.

\section{Morphogenesis}

Morphogenesis is the critical process through which tissues and organs gain their characteristic shapes. The anterior tilting of hair follicles is just one example of an increasing number of morphogenetic processes that have been linked to PCP signaling in mice. Consistent with Xenopus and zebrafish studies that have showed a central role of PCP signaling in CE, disruption of PCP signaling in mice leads to morphogenetic defects that manifest as shortening and widening of many tissues and organs, including the cochlea tube (Wang et al. 2005), stomach and intestine (Matsuyama et al. 2009). In some cases, aberrant tissue shapes in mouse PCP mutants also have profound effects that result in severe structural defects mimicking certain congenital disorders in humans. In this respect, investigation of mouse PCP mutants has been particularly instrumental in linking the mechanistic studies of PCP signaling in other model organisms with the understanding of the pathogenic mechanisms of several human birth defects. 
J. Wang et al.

\section{Neural Tube (NT) Closure}

One of the first and most characteristic morphogenetic defects found in mouse PCP mutants is a unique form of NT closure defect (NTD) called craniorachischisis, in which the entire NT from the mid-brain to the tail fails to close. Mutations in Ptk7 as well as almost all mouse core PCP genes, including Celsr $1, F z 3 / 6$, Dvl1/2/3 and Vangl1/2, cause this defect (Kibar et al. 2001; Murdoch et al. 2001; Curtin et al. 2003; Lu et al. 2004; Wang et al. 2006a,b; Etheridge et al. 2008; Torban et al. 2008). Furthermore, although Wnt5a and Ror2 null mutants per se do not display NTDs, reducing Vangl2 dosage by $50 \%$ in either mutant is sufficient to causes craniorachischisis (Qian et al. 2007; Gao et al. 2011). Therefore, Wnt5a may function together with at least one additional noncanonical Wnt ligand to regulate NT closure by activating Ror2 and Fz3/6 mediated PCP pathway.

During NT closure, the originally flat neuroepithelial sheet rolls up to form opposing neural folds, which appose and fuse along the dorsal midline to give rise to a hollow tube. Studies in Xenopus revealed that PCP signaling is required within the neuroepithelium to narrow the distance between the elevating neural folds, thereby facilitating their apposition and fusion at the dorsal midline (Wallingford and Harland 2002). In mice, we and others have found that during neurulation, the neural plate undergoes CE-like concomitant lengthening and narrowing, which can be measured as gradual increase of the length-to-width ratio (LWR) (Wang et al. 2006a; Savory et al. 2011). Disrupting PCP signaling significantly reduces LWR by 4 somite stage (ss), several hours before NT closure normally occurs (Wang et al. 2006a; Savory et al. 2011). Therefore, similar to Xenopus, PCP signaling in mice may also promote NT closure by regulating CE-like morphogenesis to reduce the width of the neural plate and shorten the distance between the opposing neural folds. Finally, in $\mathrm{Vangl}^{L p /+}$ heterozygous mutants, a moderate reduction of the LWR is associated with delayed NT closure and partially penetrant, less severe NTDs like spinal bifida (Lu et al. 2004; Wang et al. 2006a), suggesting that perturbation of PCP-regulated CE may underlie a broad spectrum of NTDs.

These findings motivated several searches for PCP gene mutations in human NTDs that occur at a frequency of 1 in 1000 live births (Juriloff and Harris 2000). Indeed, missense mutations in VANGL2 and its homolog VANGL1 have been identified in patients with spinal bifida (Kibar et al. 2007, 2009, 2011) and miscarried fetuses with cranial NT defects such as anencephaly (Lei et al. 2010). These studies showed conclusively that disruption of PCP signaling is an important causative factor of NTDs in humans. Conversely, biochemical and functional studies of these NTD-associated VANGL1/2 mutations in model organisms may also provide novel mechanistic insights into PCP signaling.

\section{Limb Skeletal Development}

Another example in which studies of mouse PCP mutants revealed important pathogenic mechanisms in human disorders is the recent finding that Wnt5a-initiated PCP signaling regulates limb morphogenesis and skeletal formation. In humans, WNT5A and ROR2 mutations are associated with two congenital skeletal disorders: brachydactyly type $\mathrm{B}$ (BDB1), characterized by loss of phalanges of the digits, and Robinow syndrome (RRS), a broader skeletal dysplasia with features such as mesomelic limb shortening (Afzal et al. 2000; Oldridge et al. 2000; Person et al. 2010). These skeletal defects are recapitulated in Wnt5a and Ror2 mutant mice, but how Wnt5a/Ror2 regulate limb skeletal formation was unclear (Yamaguchi et al. 1999a; Takeuchi et al. 2000; Topol et al. 2003; Raz et al. 2008).

Analysis of $\mathrm{Vangl2}^{\mathrm{Lp} / \mathrm{Lp}}$ mouse mutants provided the first insight that Wnt5a/Ror2 signal through the PCP pathway to regulate limb skeletal formation. In Vangl2 ${ }^{L p / L p}$ mutants, most digits lack one phalanx, resembling the digit defects in Ror2 mutant mice and human BDB1 patients. Halving Wnt5a dosage in Vangl2 ${ }^{L p / L p}$ mutants enhances the severity and penetrance of the digit defects and causes shortening of limb long bones similar to that in RRS patients, 
suggesting that Wnt5a and Vangl2 function in the same pathway and disruption of PCP signaling underlies both BDB1 and RRS (Wang et al. 2011). Consistent with this idea, Vangl2 also genetically interacts with Ror2 during limb skeletal formation and a Wnt5a $\rightarrow$ Ror2 $\rightarrow$ Vangl2 signaling cascade was proposed to be active in the limb, leading to Vangl2 phosphorylation at conserved serine/ threonine residues that are also important for its function in zebrafish $\mathrm{CE}$ (Gao et al. 2011).

Morphometric analysis revealed that by E11, before overt skeletal formation, the limb buds in Wnt5a and Vangl2 mutants already possess aberrant shape and dimensions: their length along the P-D (proximal-distal) axis is reduced, but their width along the A-P axis and their thickness along the D-V (dorsal-ventral) axis are increased (Gros et al. 2010; Wang et al. 2011). Imaging studies indicate that mesenchymal cells in wild-type limb buds display elongated morphology, directional migration, and oriented cell division, all of which align preferentially with the P-D axis. Limb mesenchymal cell in Wnt5a mutants, however, are rounded and migrate and divide without a P-D bias (Gros et al. 2010). Collectively, these results suggest that Wnt5a-initiated PCP signaling may regulate polarized cell morphology and behavior to promote limb bud P-D lengthening while simultaneous limiting its widening and thickening along the A-P and D-V axes (Gros et al. 2010).

The altered limb bud shape and dimensions in Wnt5a and Vangl2 mutants may affect limb skeletal formation in two ways (Fig. 3). First, corresponding to the shortening, widening and thickening of mutant limb buds, the limb mesenchyme-derived prechondrogenic condensates, which serve as templates for the future skeletal elements, also become shorter, wider and thicker (Yamaguchi et al. 1999a; Wang et al. 2011). Secondly, the aberrant limb bud shape and dimensions perturb the crosstalk among spatially distinct signaling centers important for limb growth, thereby disrupting distal phalanx formation. During limb development, the AER (apical ectodermal ridge), a distal ectodermal structure, is known to secret Fgf
Wnt Signaling in Mammalian Development

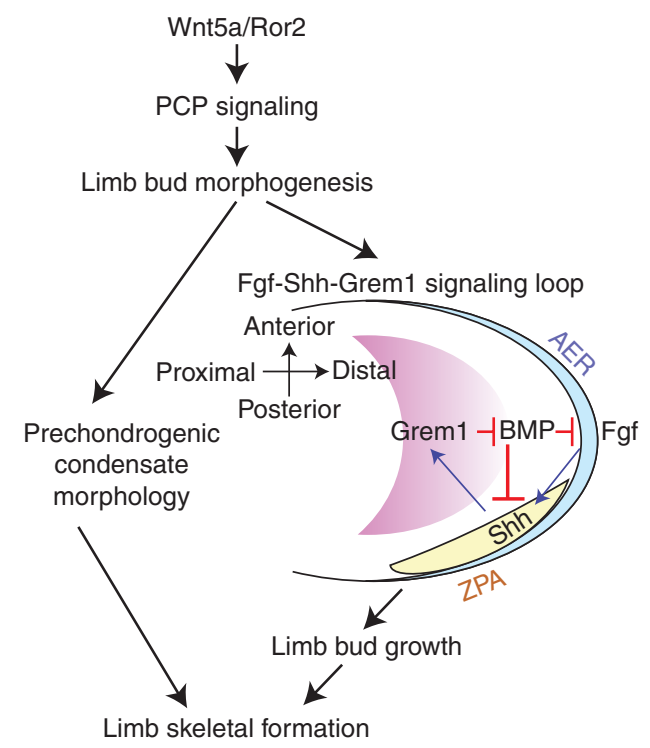

Figure 3. Wnt5a/Ror2 initiated PCP signaling regulates limb morphogenesis to promote limb skeletal formation. Wnt5a/Ror2-initiated PCP signaling regulates limb bud morphogenesis to control its shape and dimensions, which in turn ensure proper morphology of the prechondrogenic condensates in the limb and promote limb bud growth by maintaining cross-talk between spatially distinct signaling centers in the Fgf-Shh-Grem1 loop. AER: apical ectodermal ridge; Grem1: Gremlin 1; ZPA: zone of polarizing activity.

ligands (AER-Fgf) to promote cell proliferation and survival (Dudley et al. 2002; Sun et al. 2002; Yu and Ornitz 2008). AER-FGFs also stimulate limb mesenchymal cells located in the posterior ZPA (zone of polarizing activity) to produce Shh, which in turn maintains the expression of Gremlin 1 (Grem1) in the dorsal and ventral margin of the limb. Grem1 encodes an extracellular BMP inhibitor that counteracts the negative effect of Bmp on Fgf/ Shh signaling and AER maintenance (Fig. 3) (Khokha et al. 2003; Bastida et al. 2009; Benazet et al. 2009), thereby establishing the Fgf-Shh-Grem1 signaling loop to sustain limb growth. In Vangl2 and Wnt5a mutants, the abnormal limb bud thickening and widening alter the distance among the three signaling centers (the distal AER, posterior ZPA, and dorsal-ventral margin of the limb), leading to reduced robustness of the Fgf-Shh-Grem1 
J. Wang et al.

signaling loop and aberrant increase in Bmp signaling. Consequently, Fgf signaling is attenuated, resulting in limb growth defect and loss of distal phalanges. Importantly, halving Bmp4 dosage in Vangl2 ${ }^{L p / L p}$ mutants partially rescued the loss of distal phalanges (Wang et al. 2011), providing definitive evidence that elevated Bmp signaling is causative to the digit defects in PCP mutant mice and presumably, human BDB1 patients. Collectively, the recent studies on Wnt5a and PCP mutants (Gros et al. 2010; Gao et al. 2011; Wang et al. 2011) provided not only an integrated view on how limb growth and morphogenesis coordinate to regulate skeletal formation, but also novel and critical insight into the pathogenic mechanisms of RRS and BDB1.

\section{CONCLUDING REMARKS}

Over the last decade, mouse genetic studies have provided a fundamental understanding of how the evolutionarily conserved canonical Wnt pathway, through regulating $\beta$-catenin stability, controls gene expression, cell proliferation, cell fate, and embryonic patterning during various stages of mammalian development (also see reviews (van Amerongen and Berns 2006; Grigoryan et al. 2008). Wnt signaling, however, is not simply "on" or "off," and a major question remaining to be resolved is how the magnitude and duration of Wnt signaling activity impact mammalian development. Secondly, genetic studies have revealed that Wnt signaling functionally interacts with other pathways to form signaling networks that orchestrate mammalian embryogenesis. In most cases, however, we do not know the cellular and molecular mechanisms of these interactions. Answering these questions will provide great insight into stem cell biology, tissue engineering and regenerative medicine.

The rapidly expanding investigations on the mouse PCP pathway have established this noncanonical Wnt signaling branch as a central player in regulating tissue morphogenesis and cell polarity. These studies have also revealed how disrupting PCP-mediated morphogenesis can have profound effects that lead to structural defects, and provided critical insight into the etiology of human NTDs, RRS, and BDB1. The cellular basis behind PCP-mediated morphogenesis, however, remains largely unknown in mammals. At the molecular level, what are the effectors that function downstream from core PCP proteins to modulate cell behavior and polarity during mammalian development is another major question needs to be resolved in the future.

\section{ACKNOWLEDGMENTS}

JW is supported by AHA grants $0635262 \mathrm{~N}$ and 11GRNT6980004, NIH grant R01HL109130, a pilot project from NIH grant 2P30AR046031 and start-up funds from the University of Alabama at Birmingham. AWB is supported by $\mathrm{NIH}$ grants from NICHD (HD43173) and NINDS (NS73159).

\section{REFERENCES}

Afzal AR, Rajab A, Fenske CD, Oldridge M, Elanko N, Ternes-Pereira E, Tuysuz B, Murday VA, Patton MA, Wilkie AO, et al. 2000. Recessive Robinow syndrome, allelic to dominant brachydactyly type $\mathrm{B}$, is caused by mutation of ROR2. Nat Genet 25: 419-422.

Amonlirdviman K, Khare NA, Tree DR, Chen WS, Axelrod JD, Tomlin CC. 2005. Mathematical modeling of planar cell polarity to understand domineering nonautonomy. Science 307: 423-426.

Aulehla A, Wiegraebe W, Baubet V, Wahl MB, Deng C, Taketo M, Lewandoski M, Pourquie O. 2008. A $\beta$-catenin gradient links the clock and wavefront systems in mouse embryo segmentation. Nat Cell Biol 10: 186-193.

Barrow JR, Howell WD, Rule M, Hayashi S, Thomas KR, Capecchi MR, McMahon AA. 2007. Wnt3 signaling in the epiblast is required for proper orientation of the anteroposterior axis. Dev Biol 312: 312-320.

Bastida MF, Sheth R, Ros MM. 2009. A BMP-Shh negativefeedback loop restricts Shh expression during limb development. Development 136: 3779-3789.

Bayly R, Axelrod JD. 2011. Pointing in the right direction: New developments in the field of planar cell polarity. Nat Rev Genet 12: 385-391.

Ben-Haim N, Lu C, Guzman-Ayala M, Pescatore L, Mesnard D, Bischofberger M, Naef F, Robertson EJ, Constam DD. 2006. The nodal precursor acting via activin receptors induces mesoderm by maintaining a source of its convertases and BMP4. Dev Cell 11: 313-323.

Benazet JD, Bischofberger M, Tiecke E, Goncalves A, Martin JF, Zuniga A, Naef F, Zeller R. 2009. A self-regulatory system of interlinked signaling feedback loops controls mouse limb patterning. Science 323: 1050-1053.

Bilder D, Perrimon N. 2000. Localization of apical epithelial determinants by the basolateral PDZ protein Scribble. Nature 403: 676-680. 
Brennan J, Norris DP, Robertson EE. 2002. Nodal activity in the node governs left-right asymmetry. Genes Dev 16: 2339-2344.

Currier N, Chea K, Hlavacova M, Sussman DJ, Seldin DC, Dominguez I. 2010. Dynamic expression of a LEF-EGFP Wnt reporter in mouse development and cancer. Genesis 48: $183-194$.

Curtin JA, Quint E, Tsipouri V, Arkell RM, Cattanach B, Copp AJ, Henderson DJ, Spurr N, Stanier P, Fisher EM, et al. 2003. Mutation of Celsr1 disrupts planar polarity of inner ear hair cells and causes severe neural tube defects in the mouse. Curr Biol 13: 1129-1133.

Devenport D, Fuchs E. 2008. Planar polarization in embryonic epidermis orchestrates global asymmetric morphogenesis of hair follicles. Nat Cell Biol 10: 1257-1268.

Ding J, Yang L, Yan YT, Chen A, Desai N, Wynshaw-Boris A, Shen MM. 1998. Cripto is required for correct orientation of the anterior-posterior axis in the mouse embryo. Nature 395: 702-707.

Dudley AT, Ros MA, Tabin CC. 2002. A re-examination of proximodistal patterning during vertebrate limb development. Nature 418: 539-544.

Dunty WC Jr, Biris KK, Chalamalasetty RB, Taketo MM, Lewandoski M, Yamaguchi TT. 2008. Wnt3a/ $\beta$-catenin signaling controls posterior body development by coordinating mesoderm formation and segmentation. Development 135: 85-94.

Etheridge SL, Ray S, Li S, Hamblet NS, Lijam N, Tsang M, Greer J, Kardos N, Wang J, Sussman DJ, et al. 2008. Murine dishevelled 3 functions in redundant pathways with dishevelled 1 and 2 in normal cardiac outflow tract, cochlea, and neural tube development. PLoS Genet 4.

Galceran J, Farinas I, Depew MJ, Clevers H, Grosschedl R. 1999. Wnt3a $\mathrm{a}^{-/-}$-like phenotype and limb deficiency in Lef1 $^{-/-}$Tcfl $^{-/-}$mice. Genes Dev 13: 709-717.

Galceran J, Hsu SC, Grosschedl R. 2001. Rescue of a Wnt mutation by an activated form of LEF-1: Regulation of maintenance but not initiation of Brachyury expression. Proc Natl Acad Sci 98: 8668-8673.

Galceran J, Sustmann C, Hsu SC, Folberth S, Grosschedl R. 2004. LEF1-mediated regulation of Delta-like1 links Wnt and Notch signaling in somitogenesis. Genes Dev 18: $2718-2723$.

Gao B, Song H, Bishop K, Elliot G, Garrett L, English MA, Andre P, Robinson J, Sood R, Minami Y, et al. 2011. Wnt signaling gradients establish planar cell polarity by inducing Vangl2 phosphorylation through Ror2. Dev Cell 20: $163-176$.

Gong Y, Mo C, Fraser SS. 2004. Planar cell polarity signalling controls cell division orientation during zebrafish gastrulation. Nature 430: 689-693.

Grigoryan T, Wend P, Klaus A, Birchmeier W. 2008. Deciphering the function of canonical Wnt signals in development and disease: Conditional loss- and gain-of-function mutations of $\beta$-catenin in mice. Genes Dev 22: 2308-2341.

Gros J, Hu JK, Vinegoni C, Feruglio PF, Weissleder R, Tabin CC. 2010. WNT5A/JNK and FGF/MAPK pathways regulate the cellular events shaping the vertebrate limb bud. Curr Biol 20: 1993-2002.
Guo N, Hawkins C, Nathans J. 2004. Frizzled6 controls hair patterning in mice. Proc Natl Acad Sci 101: 9277-9281.

Haegel H, Larue L, Ohsugi M, Fedorov L, Herrenknecht K, Kemler R. 1995. Lack of $\beta$-catenin affects mouse development at gastrulation. Development 121: 3529-3537.

Harada N, Tamai Y, Ishikawa T, Sauer B, Takaku K, Oshima M, Taketo MM. 1999. Intestinal polyposis in mice with a dominant stable mutation of the $\beta$-catenin gene. Embo J 18: $5931-5942$.

Hashimoto M, Shinohara K, Wang J, Ikeuchi S, Yoshiba S, Meno C, Nonaka S, Takada S, Hatta K, Wynshaw-Boris A, et al. 2010. Planar polarization of node cells determines the rotational axis of node cilia. Nat Cell Biol 12: $170-176$.

Heisenberg CP, Tada M, Rauch GJ, Saude L, Concha ML, Geisler R, Stemple DL, Smith JC, Wilson SS. 2000. Silberblick/Wnt11 mediates convergent extension movements during zebrafish gastrulation. Nature 405: 76-81.

Hofmann M, Schuster-Gossler K, Watabe-Rudolph M, Aulehla A, Herrmann BG, Gossler A. 2004. WNT signaling, in synergy with T/TBX6, controls Notch signaling by regulating Dll1 expression in the presomitic mesoderm of mouse embryos. Genes Dev 18: 2712-2717.

Hsieh JC, Lee L, Zhang L, Wefer S, Brown K, DeRossi C, Wines ME, Rosenquist T, Holdener BB. 2003. Mesd encodes an LRP5/ 6 chaperone essential for specification of mouse embryonic polarity. Cell 112: 355-367.

Huelsken J, Vogel R, Brinkmann V, Erdmann B, Birchmeier C, Birchmeier W. 2000. Requirement for $\beta$-catenin in anterior-posterior axis formation in mice. $J$ Cell Biol 148: $567-578$

Jho EH, Zhang T, Domon C, Joo CK, Freund JN, Costantini F. 2002. Wnt/ $\beta$-catenin/Tcf signaling induces the transcription of Axin2, a negative regulator of the signaling pathway. Mol Cell Biol 22: 1172-1183.

Jones C, Roper VC, Foucher I, Qian D, Banizs B, Petit C, Yoder BK, Chen P. 2008. Ciliary proteins link basal body polarization to planar cell polarity regulation. Nat Genet 40: 69-77.

Juriloff DM, Harris MJ. 2000. Mouse models for neural tube closure defects. Hum Mol Genet 9: 993-1000.

Kelly OG, Pinson KI, Skarnes WW. 2004. The Wnt co-receptors Lrp5 and Lrp6 are essential for gastrulation in mice. Development 131: 2803-2815.

Kemler R, Hierholzer A, Kanzler B, Kuppig S, Hansen K, Taketo MM, de Vries WN, Knowles BB, Solter D. 2004. Stabilization of $\beta$-catenin in the mouse zygote leads to premature epithelial-mesenchymal transition in the epiblast. Development 131: 5817-5824.

Kemp C, Willems E, Abdo S, Lambiv L, Leyns L. 2005. Expression of all Wnt genes and their secreted antagonists during mouse blastocyst and postimplantation development. Dev Dyn 233: 1064-1075.

Khokha MK, Hsu D, Brunet LJ, Dionne MS, Harland RR. 2003. Gremlin is the BMP antagonist required for maintenance of Shh and Fgf signals during limb patterning. Nat Genet 34: 303-307.

Kibar Z, Vogan KJ, Groulx N, Justice MJ, Underhill DA, Gros P. 2001. Ltap, a mammalian homolog of Drosophila Strabismus/Van Gogh, is altered in the mouse neural tube mutant Loop-tail. Nat Genet 28: 251-255. 
J. Wang et al.

Kibar Z, Torban E, McDearmid JR, Reynolds A, Berghout J, Mathieu M, Kirillova I, De Marco P, Merello E, Hayes JM, et al. 2007. Mutations in VANGL1 associated with neuraltube defects. N Engl J Med 356: 1432-1437.

Kibar Z, Bosoi CM, Kooistra M, Salem S, Finnell RH, De Marco P, Merello E, Bassuk AG, Capra V, Gros P. 2009. Novel mutations in VANGL1 in neural tube defects. Hum Mutat 30.

Kibar Z, Salem S, Bosoi C, Pauwels E, De Marco P, Merello E, Bassuk A, Capra V, Gros P. 2011. Contribution of VANGL2 mutations to isolated neural tube defects. Clin Genet 80: 76-82.

Kimura-Yoshida C, Nakano H, Okamura D, Nakao K, Yonemura S, Belo JA, Aizawa S, Matsui Y, Matsuo I. 2005. Canonical Wnt signaling and its antagonist regulate anterior-posterior axis polarization by guiding cell migration in mouse visceral endoderm. Dev Cell 9: 639-650.

Lawrence PA, Casal J, Struhl G. 2004. Cell interactions and planar polarity in the abdominal epidermis of Drosophila. Development 131: 4651-4664.

Lei YP, Zhang T, Li H, Wu BL, Jin L, Wang HH. 2010. VANGL2 mutations in human cranial neural-tube defects. N Engl J Med 362: 2232-2235.

Lewis SL, Khoo PL, De Young RA, Steiner K, Wilcock C, Mukhopadhyay M, Westphal H, Jamieson RV, Robb L, Tam PP. 2008. Dkk1 and Wnt3 interact to control head morphogenesis in the mouse. Development 135: 17911801.

Lickert H, Kutsch S, Kanzler B, Tamai Y, Taketo MM, Kemler R. 2002. Formation of multiple hearts in mice following deletion of $\beta$-catenin in the embryonic endoderm. Dev Cell 3: 171-181.

Liu P, Wakamiya M, Shea MJ, Albrecht U, Behringer RR, Bradley A. 1999. Requirement for Wnt3 in vertebrate axis formation. Nat Genet 22: 361-365.

Lu X, Borchers AG, Jolicoeur C, Rayburn H, Baker JC, Tessier-Lavigne M. 2004. PTK7/CCK-4 is a novel regulator of planar cell polarity in vertebrates. Nature 430: 93-98.

Lustig B, Jerchow B, Sachs M, Weiler S, Pietsch T, Karsten U, van de Wetering M, Clevers H, Schlag PM, Birchmeier W, et al. 2002. Negative feedback loop of Wnt signaling through upregulation of conductin/axin2 in colorectal and liver tumors. Mol Cell Biol 22: 1184-1193.

Maretto S, Cordenonsi M, Dupont S, Braghetta P, Broccoli V, Hassan AB, Volpin D, Bressan GM, Piccolo S. 2003 Mapping Wnt/ $\beta$-catenin signaling during mouse development and in colorectal tumors. Proc Natl Acad Sci 100: 3299-3304.

Matsuyama M, Aizawa S, Shimono A. 2009. Sfrp controls apicobasal polarity and oriented cell division in developing gut epithelium. PLoS Genet 5: e1000427.

Miura S, Singh AP, Mishina Y. 2010. Bmprla is required for proper migration of the AVE through regulation of Dkk1 expression in the pre-streak mouse embryo. Dev Biol 341: $246-254$.

Mohamed OA, Clarke HJ, Dufort D. 2004. $\beta$-catenin signaling marks the prospective site of primitive streak formation in the mouse embryo. Dev Dyn 231: 416-424.

Mohamed OA, Jonnaert M, Labelle-Dumais C, Kuroda K Clarke HJ, Dufort D. 2005. Uterine Wnt/ $\beta$-catenin sig- naling is required for implantation. Proc Natl Acad Sci 102: $8579-8584$

Montcouquiol M, Rachel RA, Lanford PJ, Copeland NG, Jenkins NA, Kelley MM. 2003. Identification of Vangl2 and Scrb1 as planar polarity genes in mammals. Nature 423: 173-177.

Montcouquiol M, Sans N, Huss D, Kach J, Dickman JD, Forge A, Rachel RA, Copeland NG, Jenkins NA, Bogani D, et al. 2006. Asymmetric localization of Vangl2 and Fz3 indicate novel mechanisms for planar cell polarity in mammals. J Neurosci 26: 5265-5275.

Morkel M, Huelsken J, Wakamiya M, Ding J, van de Wetering $\mathrm{M}$, Clevers $\mathrm{H}$, Taketo MM, Behringer RR, Shen MM, Birchmeier W. 2003. $\beta$-catenin regulates Cripto- and Wnt3-dependent gene expression programs in mouse axis and mesoderm formation. Development 130: 62836294.

Mukhopadhyay M, Shtrom S, Rodriguez-Esteban C, Chen L, Tsukui T, Gomer L, Dorward DW, Glinka A, Grinberg A, Huang SP, et al. 2001. Dickkopf1 is required for embryonic head induction and limb morphogenesis in the mouse. Dev Cell 1: 423-434.

Murdoch JN, Doudney K, Paternotte C, Copp AJ, Stanier P. 2001. Severe neural tube defects in the loop-tail mouse result from mutation of Lpp1, a novel gene involved in floor plate specification. Hum Mol Genet 10: 2593-2601.

Nakaya MA, Biris K, Tsukiyama T, Jaime S, Rawls JA, Yamaguchi TT. 2005. Wnt3alinks left-right determination with segmentation and anteroposterior axis elongation. Development 132: 5425-5436.

Nelson WJ, Nusse R. 2004. Convergence of Wnt, $\beta$-catenin, and cadherin pathways. Science 303: 1483-1487.

Nonaka S, Yoshiba S, Watanabe D, Ikeuchi S, Goto T, Marshall WF, Hamada H. 2005. De novo formation of left-right asymmetry by posterior tilt of nodal cilia. PLoS Biol 3.

Oishi I, Suzuki H, Onishi N, Takada R, Kani S, Ohkawara B, Koshida I, Suzuki K, Yamada G, Schwabe GC, et al. 2003. The receptor tyrosine kinase Ror2 is involved in noncanonical Wnt5a/JNK signalling pathway. Genes Cells 8: $645-654$.

Okada Y, Takeda S, Tanaka Y, Belmonte JC, Hirokawa N 2005. Mechanism of nodal flow: A conserved symmetry breaking event in left-right axis determination. Cell 121: 633-644.

Oldridge M, Fortuna AM, Maringa M, Propping P, Mansour S, Pollitt C, DeChiara TM, Kimble RB, Valenzuela DM Yancopoulos GD, et al. 2000. Dominant mutations in ROR2, encoding an orphan receptor tyrosine kinase, cause brachydactyly type B. Nat Genet 24: 275-278.

Perea-Gomez A, Vella FD, Shawlot W, Oulad-Abdelghani M, Chazaud C, Meno C, Pfister V, Chen L, Robertson E, Hamada H, et al. 2002. Nodal antagonists in the anterior visceral endoderm prevent the formation of multiple primitive streaks. Dev Cell 3: 745-756.

Person AD, Beiraghi S, Sieben CM, Hermanson S, Neumann AN, Robu ME, Schleiffarth JR, Billington CJ, van Bokhoven H, Hoogeboom JM, et al. 2010. WNT5A mutations in patients with autosomal dominant Robinow syndrome. Dev Dyn 239: 327-337.

Pourquie O. 2011. Vertebrate segmentation: From cyclic gene networks to scoliosis. Cell 145: 650-663. 
Povelones M, Howes R, Fish M, Nusse R. 2005. Genetic evidence that Drosophila frizzled controls planar cell polarity and Armadillo signaling by a common mechanism. Genetics 171: 1643-1654.

Qian D, Jones C, Rzadzinska A, Mark S, Zhang X, Steel KP, Dai X, Chen P. 2007. Wnt5a functions in planar cell polarity regulation in mice. Dev Biol 306: 121-133.

Raz R, Stricker S, Gazzerro E, Clor JL, Witte F, Nistala H, Zabski S, Pereira RC, Stadmeyer L, Wang X, et al. 2008. The mutation ROR2W749X, linked to human BDB, is a recessive mutation in the mouse, causing brachydactyly, mediating patterning of joints and modeling recessive Robinow syndrome. Development 135: 1713-1723.

Rida PC, Chen P. 2009. Line up and listen: Planar cell polarity regulation in the mammalian inner ear. Semin Cell Dev Biol 20: 978-985.

Robertson EJ, Norris DP, Brennan J, Bikoff EE. 2003. Control of early anterior-posterior patterning in the mouse embryo by TGF- $\beta$ signalling. Philos Trans $R$ Soc Lond B Biol Sci 358.

Roszko I, Sawada A, Solnica-Krezel L. 2009. Regulation of convergence and extension movements during vertebrate gastrulation by the Wnt/PCP pathway. Semin Cell Dev Biol 20: 986-997.

Satoh K, Kasai M, Ishidao T, Tago K, Ohwada S, Hasegawa Y, Senda T, Takada S, Nada S, Nakamura T, et al. 2004 Anteriorization of neural fate by inhibitor of $\beta$-catenin and $\mathrm{T}$ cell factor (ICAT), a negative regulator of Wnt signaling. Proc Natl Acad Sci 101: 8017-8021.

Savory JG, Mansfield M, Rijli FM, Lohnes D. 2011. Cdx mediates neural tube closure through transcriptional regulation of the planar cell polarity gene Ptk7. Development 138: $1361-1370$.

Seifert JR, Mlodzik M. 2007. Frizzled/PCP signalling: A conserved mechanism regulating cell polarity and directed motility. Nat Rev Genet 8: 126-138.

Song H, Hu J, Chen W, Elliott G, Andre P, Gao B, Yang Y. 2010. Planar cell polarity breaks bilateral symmetry by controlling ciliary positioning. Nature 466: 378-382.

Strutt H, Strutt D. 2009. Asymmetric localisation of planar polarity proteins: Mechanisms and consequences. Semin Cell Dev Biol 20: 957-963.

Stuckey DW, Clements M, Di-Gregorio A, Senner CE, Le Tissier P, Srinivas S, Rodriguez TT. 2011. Coordination of cell proliferation and anterior-posterior axis establishment in the mouse embryo. Development 138: 15211530.

Sun X, Meyers EN, Lewandoski M, Martin GG. 1999. Targeted disruption of Fgf8 causes failure of cell migration in the gastrulating mouse embryo. Genes Dev 13: 18341846.

Sun X, Mariani FV, Martin GG. 2002. Functions of FGF signalling from the apical ectodermal ridge in limb development. Nature 418: 501-508.

Takada S, Stark KL, Shea MJ, Vassileva G, McMahon JA, McMahon AA. 1994. Wnt-3a regulates somite and tailbud formation in the mouse embryo. Genes Dev 8: 174-189.

Takeuchi S, Takeda K, Oishi I, Nomi M, Ikeya M, Itoh K, Tamura S, Ueda T, Hatta T, Otani H, et al. 2000. Mouse
Ror2 receptor tyrosine kinase is required for the heart development and limb formation. Genes Cells 5: 71-78.

Tao H, Suzuki M, Kiyonari H, Abe T, Sasaoka T, Ueno N. 2009. Mouse prickle1, the homolog of a PCP gene, is essential for epiblast apical-basal polarity. Proc Natl Acad Sci 106: 14426-14431.

ten Berge D, Koole W, Fuerer C, Fish M, Eroglu E, Nusse R. 2008. Wnt signaling mediates self-organization and axis formation in embryoid bodies. Cell Stem Cell 3: 508-518.

ten Berge D, Kurek D, Blauwkamp T, Koole W, Maas A, Eroglu E, Siu RK, Nusse R. 2011. Embryonic stem cells require Wnt proteins to prevent differentiation to epiblast stem cells. Nat Cell Biol 13: 1070-1075.

Topol L, Jiang X, Choi H, Garrett-Beal L, Carolan PJ, Yang Y. 2003. Wnt-5a inhibits the canonical Wnt pathway by promoting GSK-3-independent $\beta$-catenin degradation. J Cell Biol 162: 899-908.

Torban E, Patenaude AM, Leclerc S, Rakowiecki S, Gauthier S, Andelfinger G, Epstein DJ, Gros P. 2008. Genetic interaction between members of the Vangl family causes neural tube defects in mice. Proc Natl Acad Sci 105: 34493454.

van Amerongen R, Berns A. 2006. Knockout mouse models to study Wnt signal transduction. Trends Genet 22: $678-689$.

Veeman MT, Axelrod JD, Moon RR. 2003. A second canon. Functions and mechanisms of $\beta$-catenin-independent Wnt signaling. Dev Cell 5: 367-377.

Wallingford JB, Habas R. 2005. The developmental biology of Dishevelled: An enigmatic protein governing cell fate and cell polarity. Development 132: 4421-4436.

Wallingford JB, Harland RM. 2002. Neural tube closure requires Dishevelled-dependent convergent extension of the midline. Development 129: 5815-5825.

Wallingford JB, Rowning BA, Vogeli KM, Rothbacher U, Fraser SE, Harland RR. 2000. Dishevelled controls cell polarity during Xenopus gastrulation. Nature 405: 8185.

Wang J, Mark S, Zhang X, Qian D, Yoo SJ, Radde-Gallwitz K, Zhang Y, Lin X, Collazo A, Wynshaw-Boris A, et al. 2005. Regulation of polarized extension and planar cell polarity in the cochlea by the vertebrate PCP pathway. Nat Genet 37: $980-985$.

Wang J, Hamblet NS, Mark S, Dickinson ME, Brinkman BC, Segil N, Fraser SE, Chen P, Wallingford JB, WynshawBoris A. 2006a. Dishevelled genes mediate a conserved mammalian PCP pathway to regulate convergent extension during neurulation. Development 133: $1767-$ 1778.

Wang Y, Guo N, Nathans J. 2006b. The role of Frizzled3 and Frizzled6 in neural tube closure and in the planar polarity of inner-ear sensory hair cells. J Neurosci 26: 2147-2156.

Wang B, Sinha T, Jiao K, Serra R, Wang J. 2011. Disruption of PCP signaling causes limb morphogenesis and skeletal defects and may underlie Robinow syndrome and brachydactyly type B. Hum Mol Genet 20: 271-285.

Wehner P, Shnitsar I, Urlaub H, Borchers A. 2011. RACK1 is a novel interaction partner of PTK7 that is required for neural tube closure. Development 138: 1321-1327. 


\section{J. Wang et al.}

Wu J, Mlodzik M. 2008. The frizzled extracellular domain is a ligand for Van Gogh/Stbm during nonautonomous planar cell polarity signaling. Dev Cell 15: 462-469.

Yamaguchi TP. 2008. Genetics of Wnt signaling during early mammalian development. Methods Mol Biol 468: 287305.

Yamaguchi TP, Bradley A, McMahon AP, Jones S. 1999a. A Wnt5a pathway underlies outgrowth of multiple structures in the vertebrate embryo. Development 126: 1211 1223.

Yamaguchi TP, Takada S, Yoshikawa Y, Wu N, McMahon AA 1999b. T (Brachyury) is a direct target of Wnt3a during paraxial mesoderm specification. Genes Dev 13: 31853190.
Yamamoto S, Nishimura O, Misaki K, Nishita M, Minami Y, Yonemura S, Tarui H, Sasaki H. 2008. Cthrcl selectively activates the planar cell polarity pathway of Wnt signaling by stabilizing the Wnt-receptor complex. Dev Cell 15: 23-36.

Yoshikawa Y, Fujimori T, McMahon AP, Takada S. 1997. Evidence that absence of Wnt-3a signaling promotes neuralization instead of paraxial mesoderm development in the mouse. Dev Biol 183: 234-242.

Yu K, Ornitz DM. 2008. FGF signaling regulates mesenchymal differentiation and skeletal patterning along the limb bud proximodistal axis. Development 135: 483-491.

Zallen JA. 2007. Planar polarity and tissue morphogenesis. Cell 129: 1051-1063. 


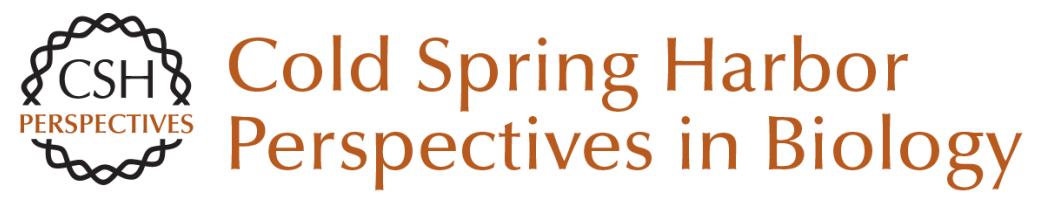

\section{Wnt Signaling in Mammalian Development: Lessons from Mouse Genetics}

Jianbo Wang, Tanvi Sinha and Anthony Wynshaw-Boris

Cold Spring Harb Perspect Biol 2012; doi: 10.1101/cshperspect.a007963

Subject Collection Wnt Signaling

Wnt Signaling in Vertebrate Axis Specification

Hiroki Hikasa and Sergei Y. Sokol

Secreted and Transmembrane Wnt Inhibitors and

Activators

Cristina-Maria Cruciat and Christof Niehrs

Wnt Signaling in Normal and Malignant

Hematopoiesis

William Lento, Kendra Congdon, Carlijn Voermans, et al.

Frizzled and LRP5/6 Receptors for Wnt/ $\beta$-Catenin Signaling

Bryan T. MacDonald and Xi He

TCF/LEFs and Wnt Signaling in the Nucleus

Ken M. Cadigan and Marian L. Waterman

\section{Alternative Wnt Pathways and Receptors Renée van Amerongen}

$\beta$-Catenin-Dependent Wnt Signaling in C. elegans: Teaching an Old Dog a New Trick

Belinda M. Jackson and David M. Eisenmann

The Evolution of the Wnt Pathway

Thomas W. Holstein
The $\beta$-Catenin Destruction Complex

Jennifer L. Stamos and William I. Weis

Wnt Signaling in Skin Development, Homeostasis, and Disease Xinhong Lim and Roel Nusse

Wnt Signaling in Bone Development and Disease:

Making Stronger Bone with Wnts Jean B. Regard, Zhendong Zhong, Bart $O$. Williams, et al.

Targeting Wnt Pathways in Disease Zachary F. Zimmerman, Randall T. Moon and Andy J. Chien

Wnt Signaling in Mammary Glands: Plastic Cell

Fates and Combinatorial Signaling Caroline M. Alexander, Shruti Goel, Saja A. Fakhraldeen, et al.

Wnt Signaling and Injury Repair Jemima L. Whyte, Andrew A. Smith and Jill A. Helms

Wnt Signaling and Forebrain Development Susan J. Harrison-Uy and Samuel J. Pleasure

Wnt Signaling in Neuromuscular Junction Development

Kate Koles and Vivian Budnik

For additional articles in this collection, see http://cshperspectives.cshlp.org/cgi/collection/

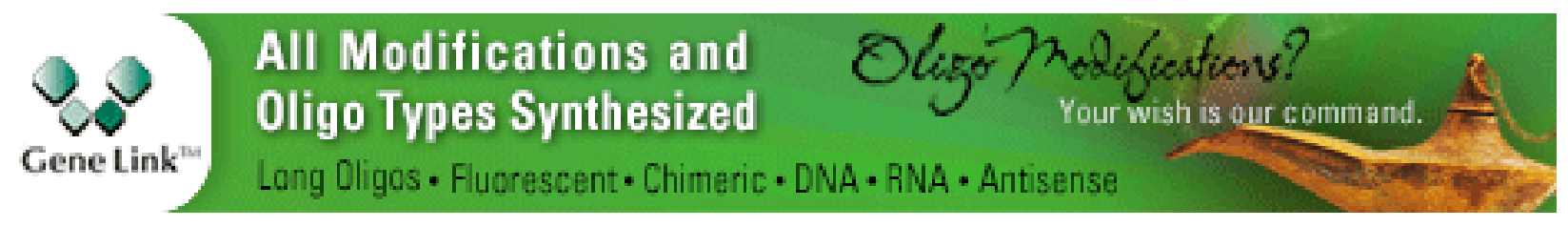

Copyright @ 2012 Cold Spring Harbor Laboratory Press; all rights reserved 